\title{
XPG rs2296147 T>C polymorphism predicted clinical outcome in colorectal cancer
}

\author{
Fang Wang ${ }^{1, *}$, Shao-Dan Zhang ${ }^{1, *}$, Hong-Mei $\mathrm{Xu}^{3, *}$, Jin-Hong Zhu ${ }^{4}$, Rui-Xi Hua ${ }^{5}$, \\ Wen-Qiong Xue ${ }^{1}$, Xi-Zhao Li ${ }^{1}$, Tong-Min Wang ${ }^{1}$, Jing He ${ }^{1,2}$, Wei-Hua Jia ${ }^{1}$ \\ ${ }^{1}$ Sun Yat-Sen University Cancer Center, State Key Laboratory of Oncology in South China, Department of Experimental \\ Research, Collaborative Innovation Center for Cancer Medicine, Guangzhou 510060, Guangdong, China \\ ${ }^{2}$ Department of Pediatric Surgery, Guangzhou Women and Children's Medical Center, Guangzhou Medical University, \\ Guangzhou 510623, Guangdong, China \\ ${ }^{3}$ Reproductive Medical Center, Department of Obstetrics and Gynecology, Sun Yat-Sen Memorial Hospital, Guangzhou \\ 510120, Guangdong, China \\ ${ }^{4}$ Molecular Epidemiology Laboratory and Department of Laboratory Medicine, Harbin Medical University Cancer Hospital, \\ Harbin 150081, Heilongjiang, China \\ ${ }^{5}$ Department of Oncology, The First Affiliated Hospital of Sun Yat-Sen University, Guangzhou 510080, Guangdong, China \\ *These authors contributed equally to this work
}

Correspondence to: Jing He, e-mail: hejing198374@gmail.com

Wei-Hua Jia, e-mail: jiaweih@mail.sysu.edu.cn

Keywords: colorectal cancer, xeroderma pigmentosum group G, single nucleotide polymorphism, progression-free survival, overall survival

Received: September 22, 2015

Accepted: January 23, 2016

Published: February 12, 2016

\section{ABSTRACT}

Xeroderma pigmentosum group G (XPG), one of key components of nucleotide excision repair pathway (NER), is involved in excision repair of UV-induced DNA damage. Single nucleotide polymorphisms (SNPs) in the XPG gene have been reported to associate with the clinical outcome of various cancer patients. We aimed to assess the impact of four potentially functional SNPs ( rs2094258 C>T, rs2296147 T>C, rs751402 G>A, and rs873601 G>A) in the XPG gene on prognosis in colorectal cancer (CRC) patients. A total of 1901 patients diagnosed with pathologically confirmed CRC were genotyped for four XPG polymorphisms. Cox proportional hazards model analysis controlled for several confounding factors was conducted to compute hazard ratios (HRs) and 95\% confidence intervals (CIs). Of the four included SNPs, only rs2296147 was shown to significantly affect progression-free survival (PFS) in CRC. Patients carrying rs2296147 CT/TT genotype had a significantly shorter median 10 years PFS than those carrying CC genotype (88.5 months vs. 118.1 months), and an increased progression risk were observed with rs2296147 ( $\mathrm{HR}=1.324,95 \% \mathrm{CI}=1.046-1.667)$. Moreover, none of the four SNPs were associated with overall survival. In conclusion, our study showed that XPG rs2296147 CT/TT variants conferred significant survival disadvantage in CRC patients in term of PFS. XPG rs2296147 polymorphism could be predictive of unfavorable prognosis of CRC patients.

\section{INTRODUCTION}

Colorectal cancer (CRC) is the third most common cancer and the fourth leading cause of cancer-related death in the world (http://globocan.iarc.fr/Pages/fact_sheets cancer.aspx). Incidence of CRC dramatically varies from region to region. It ranks fifth in the commonly diagnosed malignancies in China, with 253, 427 new cases diagnosed and 139, 416 cancer deaths in 2012 (http://globocan.iarc. fr/Pages/fact_sheets_population.aspx).

It ranks the third in the commonly diagnosed malignancies in males and the second in females, with 1.4 million new cases diagnosed and 693, 900 cancer deaths in 2012 [1]. Therefore, it remains a major public health problem in China. Physicians make treatment plan depending on the clinical stage, performance status, and molecular characteristic 
of the tumor. Generally, surgery is used to treat the early stage of $\mathrm{CRC}$, while the combination of 5-fluorouracil (5-FU), irinotecan, and oxaliplatin (FOLFOXIRI) is administrated to late-stage patients as the standard first-line chemotherapy to improve the prognosis [2]. The prognosis of colorectal cancer has been gradually improved over the past decades, with a 5 -year relative survival of $65 \%$ and less than $50 \%$ in highand low-income countries, respectively [3].

$\mathrm{CRC}$ is a complex disease, and both environmental and genetic factors contribute to oncogenesis. Diet (e.g., red meat) [4], smoking [5], drinking [6] and obesity [7] are well-known risk factors for $\mathrm{CRC}$, although the underlying mechanisms remain clarified. Apart from those environmental factors, numerous evidence suggests that DNA repair systems also play an important role in modifying the risk of CRC [8-10]. For example, SNPs in XPD have an effect on the prognosis of CRC patients who were treated with oxaliplatin and 5-fluorouracil. Comparing to XPD 751Lys/Lys genotype, patients carrying Lys/Gln genotypes had more prone to chemotherapy failure and patients carrying $\geq 1$ Gln had shorter median disease progression [8]. DNA repair systems include nucleotide excision repair (NER), base excision repair (BER), mis-match repair (MMR) and double-strand break repair (DSBR) pathways [11]. Of them, NER is responsible for repairing ultraviolet light (UV)-DNA damage, bulky DNA adducts (thymine dimers and 6, 4-photoproducts). NER functions properly by orchestrating different functional proteins involved in this pathway for the recognition of DNA lesion, incision, repair, and ligation [12]. Xeroderma pigmentosum group G (XPG) is one of the critical proteins in the NER pathway, encoded by excision repair cross-complementation group 5 (ERCC5) [12]. Accumulating studies have shown that the functional single nucleotide polymorphisms (SNPs) in the XPG gene may modify DNA repair capacity, and consequently increase the instability of genome. Additionally, such SNPs may also influence the ability to repair DNA damage caused by chemotherapeutic drugs, which enhances chemotherapeutic sensitivity and improve prognosis of CRC patients [13-15]. $X P G$ is located on chromosome $13 \mathrm{q} 33$, containing 15 exons. Its protein product, an 1186-amino acid protein, is a structure-specific endonuclease responsible for the $3^{\prime}$ incision of DNA damage during NER, which has preference for the binding site of the single strand and the double strand of the degeneration bubble [16].

It has been reported that the SNPs in the XPG gene play a vital role in the outcomes of various cancers, including gastric carcinoma $[17,18]$, non-small cell lung cancer (NSCLC) [19], breast cancer [20]. However, the association between $\mathrm{CRC}$ and $X P G$ polymorphisms remain controversial [21]. Therefore, the aim of our study was to assess the association of four potentially functional SNPs of $X P G$ (rs2094258 C $>$ T, rs2296147 T>C, rs 751402 $\mathrm{G}>\mathrm{A}$, and rs873601 $\mathrm{G}>\mathrm{A}$ ) with over-all survival (OS) and progression-free survival (PFS) of CRC in 1901 Chinese CRC patients.

\section{RESULTS}

\section{Patient characteristics and clinicopathological cutcomes}

The demographic and clinicopathological characteristics of 1901 patients were shown in Table 1. Patients aged between 13 to 91 years, with a median age of 57.05 years. Body mass index (BMI) ranged from 13.19-41.36 (median: 22.38 ) and $60.5 \%$ of the patients were males. Most of patients did not have unhealthy lifestyle, such as smoking and drinking, and most of the patients with later Dukes stages. Patients with rectum and colon cancer accounted for $54.2 \%$ and $45.8 \%$ of CRC, respectively. After surgery and chemotherapy, $96.8 \%$ patients showed good response and about $1 / 3$ patients later underwent recurrence or metastasis.

\section{Association between XPG SNPs and prognosis of CRC}

Genotype frequency distributions of four XPG SNPs were summarized in Table 2. The SNPs were analyzed for association with PFS and OS in patients with CRC. A significant association was found between $X P G$ rs 2296147 variant genotypes and PFS in CRC. $X P G$ rs $2296147 \mathrm{~T}>\mathrm{C}$ polymorphism led to a decrease in median 10-year PFS time of 88.5 months for carriers of rs2296147 CT/TT genotype, when compared with 118.1 months for patients with CC genotype (log-rank test, $P=0.020$ ) (Figure 1). Univariate Cox proportional hazards model analysis indicated that age, BMI, dukes stage, recurrence/metastasis status, and therapeutic response could influence 10 years OS or PFS (Table 3). After adjusting for those potential confounding factors, multivariate Cox proportional hazards model showed that patients carrying rs2296147 CT/TT genotype had an the hazard ratios (HR) of 1.324 (95\% CI $=1.046-1.667)$ for developing progression in comparison non-carriers. It suggested that XPG rs2296147 CT/TT genotype might be an independent predictor of poor prognosis in CRC (Table 4). No association with PFS was observed for other SNPs (rs2094258, rs 751402 and rs873601). Moreover, we failed to find any significant association for the XPG rs2296147 with 10-year OS (Figure 2), as well as the other three polymorphisms.

\section{DISCUSSION}

In the present study, we found that $X P G$ rs 2296147 CT/TT genotypes were correlated with poor 10-year PFS in CRC when compared with CC genotype. In other words, XPG rs2296147 CC genotype was associated with favorable prognosis regarding 10- year PFS, suggesting that $X P G$ rs2296147 CC homozygous variation is a protective factor for the 10 years PFS in CRC. However, incidence of this homozygous variation is relatively low. There was no 
Table 1: Demographic and clinical data of patients

\begin{tabular}{|c|c|c|}
\hline Variables & Number & Range/Percentage (\%) \\
\hline Age (years) 58.00 & $916(>58.00)$ & 13-91 (range) \\
\hline BMI (weight/hight ${ }^{2}$ ) 22.23 & $840(>22.23)$ & 13.19-41.36 (range) \\
\hline Patients with PFS & 1516 & 79.7 \\
\hline Patients without PFS & 385 & 20.3 \\
\hline \multicolumn{3}{|l|}{ Sex } \\
\hline Male & 1150 & 60.5 \\
\hline Female & 751 & 39.5 \\
\hline \multicolumn{3}{|l|}{ Smoking status } \\
\hline Never & 1381 & 73.2 \\
\hline Ever & 505 & 26.8 \\
\hline \multicolumn{3}{|l|}{ Drinking status } \\
\hline Never & 1599 & 85.0 \\
\hline Ever & 282 & 15.0 \\
\hline \multicolumn{3}{|l|}{ Dukes stage } \\
\hline A & 207 & 10.9 \\
\hline $\mathrm{B}$ & 629 & 33.2 \\
\hline $\mathrm{C}$ & 608 & 32.1 \\
\hline $\mathrm{D}$ & 449 & 23.7 \\
\hline \multicolumn{3}{|l|}{ Tumor site } \\
\hline Rectum & 977 & 54.2 \\
\hline Colon & 824 & 45.8 \\
\hline \multicolumn{3}{|l|}{ Therapeutic response } \\
\hline Better & 1716 & 96.8 \\
\hline Worse & 57 & 3.2 \\
\hline \multicolumn{3}{|l|}{ Recurrence/Metastasis status } \\
\hline No & 1197 & 63.0 \\
\hline Yes & 704 & 37.0 \\
\hline \multicolumn{3}{|l|}{ Therapeutic methods } \\
\hline Surgery & 1001 & 52.7 \\
\hline Chemotherapy & 708 & 37.2 \\
\hline Radiotherapy & 59 & 3.1 \\
\hline
\end{tabular}

BMI, body mass index.

significant association between the rest of polymorphisms and clinical outcome of CRC patients.

$X P G$ gene is mapped to chromosome 13q33, encoding an 1186 amino acid structure-specific endonuclease. During the process of NER, XPG is involved in the incision on $5^{\prime}$ side of damage and the maintenance of stability of TFIIH. Up to now, although an increasing number of studies focus on the common genetic variations in the NER pathway, studies on the association of $X P G$ SNPs and the clinical outcome of CRC patients were limited. To the best of our knowledge, our study was the first large-scale case study to investigate the relationship between XPG polymorphisms of and prognosis of CRC. The $X P G$ polymorphisms have been reported to affect the 
Table 2: Kaplan-Meier method and Cox proportional hazards model analysis of associations between the genotypes of $X P G$ and $C R C$ prognosis

\begin{tabular}{|c|c|c|c|c|c|c|c|c|c|c|}
\hline \multirow[b]{2}{*}{ Variants } & \multicolumn{5}{|c|}{10 years $O S$} & \multicolumn{5}{|c|}{10 years PFS } \\
\hline & event & $\begin{array}{c}\text { Median } \\
\text { (months) }\end{array}$ & Log-rank $\boldsymbol{P}$ & HR (95\% CI) & $P^{\text {a }}$ & event & $\begin{array}{c}\text { Median } \\
\text { (months) }\end{array}$ & Log-rank $P$ & HR $(95 \% C I)$ & $P^{b}$ \\
\hline \multicolumn{11}{|l|}{ rs 2094258} \\
\hline TT & 83 & 106.067 & & 1.000 & & 76 & 87.667 & & 1.000 & \\
\hline $\mathrm{CT}$ & 254 & 21.267 & 0.357 & $0.973(0.747,1.268)$ & 0.842 & 208 & 98.633 & 0.169 & $0.85(0.655,1.108)$ & 0.232 \\
\hline $\mathrm{CC}$ & 265 & 119.800 & 0.945 & $0.942(0.724,1.223)$ & 0.649 & 227 & 83.967 & 0.728 & $1.019(0.785,1.323)$ & 0.889 \\
\hline $\mathrm{CT} / \mathrm{CC}$ & 519 & 119.800 & 0.600 & $0.978(0.865,1.106)$ & 0.722 & 435 & 92.033 & 0.363 & $0.964(0.854,1.090)$ & 0.561 \\
\hline \multicolumn{11}{|l|}{ rs 2296147} \\
\hline $\mathrm{CC}$ & 25 & 20.067 & & 1.000 & & 18 & 118.067 & & 1.000 & \\
\hline $\mathrm{CT}$ & 200 & 119.800 & 0.392 & $1.381(0.837,2.276)$ & 0.206 & 178 & 84.867 & 0.024 & $1.780(1.093,2.898)$ & 0.021 \\
\hline $\mathrm{TT}$ & 377 & 119.867 & 0.258 & $1.492(0.915,2.433)$ & 0.108 & 315 & 89.567 & 0.025 & $1.740(1.080,2.803)$ & 0.023 \\
\hline $\mathrm{CT} / \mathrm{TT}$ & 577 & 119.800 & 0.267 & $1.205(0.946,1.535)$ & 0.131 & 493 & 88.500 & 0.020 & $1.324(1.046,1.667)$ & 0.020 \\
\hline \multicolumn{11}{|l|}{ rs 751402} \\
\hline AA & 83 & 119.867 & & 1.000 & & 76 & 83.867 & & 1.000 & \\
\hline $\mathrm{AG}$ & 263 & 119.800 & 0.489 & $0.953(0.733,1.240)$ & 0.721 & 216 & 89.133 & 0.384 & $0.851(0.655,1.107)$ & 0.851 \\
\hline GG & 256 & 117.800 & 0.567 & $0.893(0.688,1.161)$ & 0.399 & 219 & 92.033 & 0.521 & $0.830(0.639,1.080)$ & 0.830 \\
\hline $\mathrm{AG} / \mathrm{GG}$ & 519 & 119.800 & 0.478 & $0.960(0.850,1.085)$ & 0.515 & 435 & 91.233 & 0.414 & $0.917(0.811,1.036)$ & 0.165 \\
\hline \multicolumn{11}{|l|}{ rs873601 } \\
\hline AA & 155 & 117.800 & & 1.000 & & 144 & 85.300 & & 1.000 & \\
\hline $\mathrm{AG}$ & 286 & 119.800 & 0.347 & $1.028(0,831,1.272)$ & 0.799 & 227 & 92.900 & 0.119 & $0.856(0.694,1.056)$ & 0.856 \\
\hline GG & 161 & 119.867 & 0.822 & $0.994(0.780,1.267)$ & 0.964 & 140 & 93.267 & 0.502 & $0.969(0.766,1.226)$ & 0.969 \\
\hline AG/GG & 447 & 119.800 & 0.574 & $1.008(0.912,1.113)$ & 0.877 & 367 & 93.267 & 0.162 & $0.946(0.859,1.043)$ & 0.265 \\
\hline
\end{tabular}

CRC, colorectal cancer; HR, hazard ratio; CI, confidence interval; OS, overall survival; PFS, progression-free survival.

a, $P$ values were calculated after adjustment for BMI, dukes stage, recurrence/metastasis status and therapeutic response.

b, $P$ values were calculated after adjustment for age and dukes stage.

platinum-based chemotherapy sensitivity and prognosis of various cancers, including gastric cancer [18] and NSCLC [22]. Zhou et al. [19] found XPG rs2296147 and rs2094258 polymorphisms were associated with PFS and OS in NSCLC. Zhang et al. [23] also reported that down-regulation of XPG activity caused by rs 2296147 polymorphism was correlated with increased OS. There are a number of studies evaluating the influence of the $X P G$ SNPs on the risk and therapeutic response of CRC $[15,24-26]$; however few have explored the association of $X P G$ SNPs with the prognosis of CRC patients. CRC is one of the most common cancer worldwide, with approximately $55 \%$ of the cases occurring in the developed regions. So far, very few CRC-related studies involve Chinese populations $[27,28]$. The current study might be the largest one that investigated the association of interest solely in Chinese by far. The association of polymorphisms in the NER pathway with CRC remains inconclusive. Moreno et al. [14] carried out a case-control study to assess gene-environment interactions by genotyping 28 SNPs in the 15 DNA repair genes among 377 CRC patients and 329 controls. Their results highlighted the important influence of SNPs in the DNA repair genes on the response to chemotherapy and prognosis of CRC patients. Meanwhile, Du et al. [25] found that $X P G$ Asp1104His polymorphism was associated with a significantly increased risk of CRC, especially in Asian populations. However, Mort et al. [29] investigated polymorphisms in the NER genes ( $X P D, X P F$, $X P G, E R C C 1)$ and failed to prove the important role of studied SNPs in protection against CRC. Zhu et al. [30] performed a meta-analysis to explore the relationship between the ERCC5/XPG Asp1104His polymorphism and cancer risk under the recessive genetic model, and found null association between the polymorphism and the risk of CRC. In contrast, our large-scale study provided evidence of the robust association between the XPG SNPs and the prognosis of CRC patients.

The $X P G$ rs2296147 polymorphism is located in the $5^{\prime}$ untranslated regions (UTR), which was predicted to influence activity of transcription factor binding sites 
(TFBS) [31]. Cartharius et al. [32] found that $X P G$ rs2296147 is a putative P53 transcription factor-binding site. Blomquist et al. [33] found that XPG rs2296147 is associated with altered allele-specific expression of XPG transcript in normal human bronchial epithelium, so the rs2296147 polymorphism may be important to XPG expression. Our study is the first one to validate the association between XPG rs2296147 polymorphism and risk of $\mathrm{CRC}$, previous studies focus on how this site act on the clinical outcome of platinum-based chemotherapy in NSCLC patients $[19,22,23,34,35]$, susceptibility of prostate cancer patients [36, 37], gastric cancer [38, 39], and breast cancer [20], but the number was limited. Our study is the first one to clarify the relationship between rs2296147 polymorphism and CRC survival.

In conclusion, our results indicated that $X P G$ rs2296147 CT/TT was correlated with the prognosis of CRC patients. XPG rs2296147 polymorphism could be used as an independent predictive marker for the prognosis in CRC. Our study identified prognostic value of $X P G$ SNPs. It might also serve as a molecular biomarker in individualized treatmen of colorectal cancer in future.

\section{MATERIALS AND METHODS}

\section{Subject}

A total of 1901 patients with histologically confirmed colorectal carcinoma were recruited from Sun Yat-Sen University Cancer Center between January 2000 to May 2010. We recruited patients without restrictions on age, sex, ethnicity, or clinical stage. We gained demographic and clinical data from medical record review, including age, sex, smoking status, drinking status, tumor site, therapeutic response, recurrence/metastasis status, and Dukes stage. Individuals who smoked cigarettes less than 1 package were defined as never smokers, while the others were ever smokers. An individual who drank alcohol less than $50 \mathrm{ml}$ was defined as a never drinker, while the others were ever drinkers. All the patients were followed-up every year by telephone and deaths were recorded and confirmed by local Public Security Bureau until April 2015. All patients with informed consent donated their blood sample for the study.

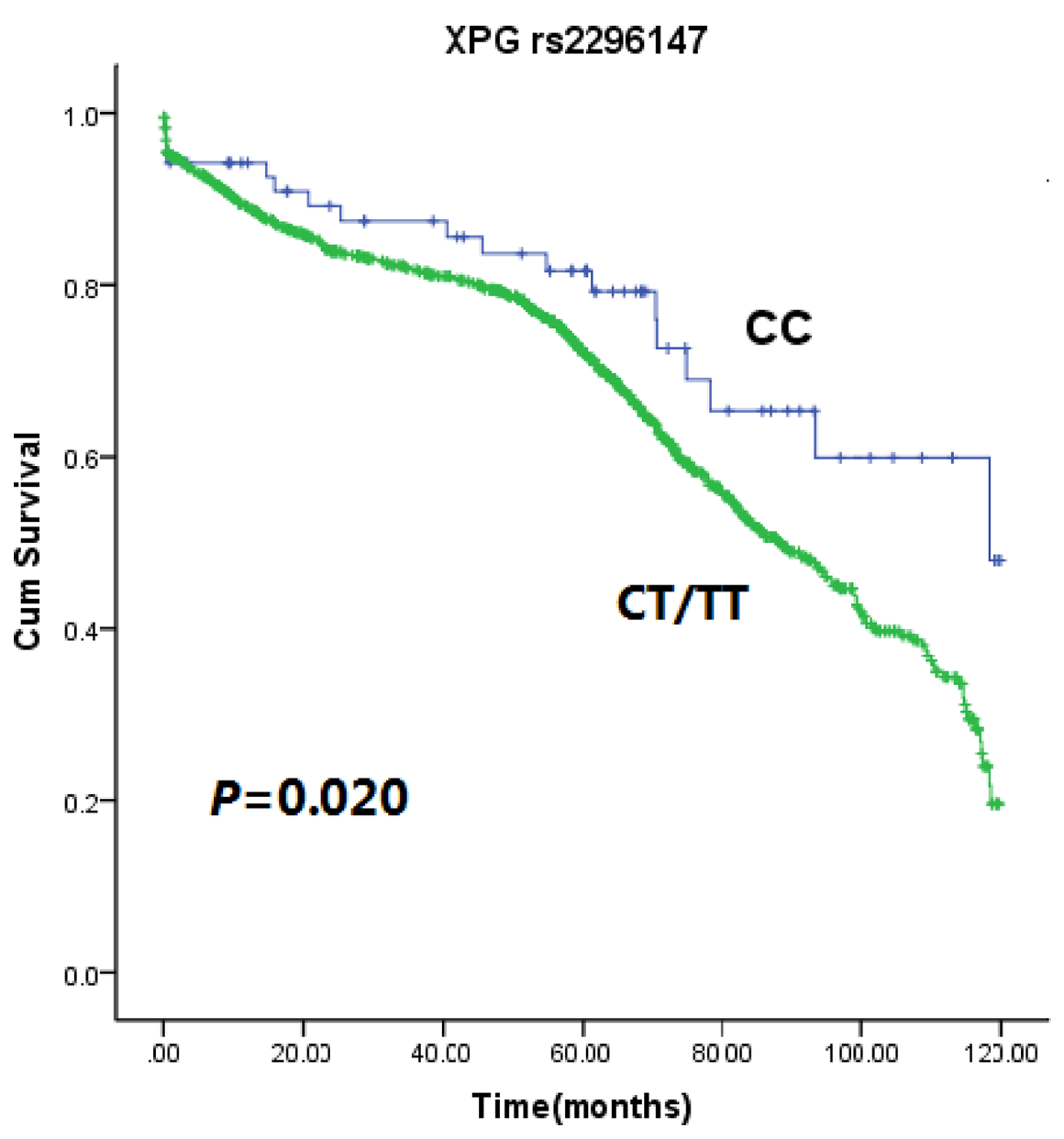

Figure 1: Kaplan-Meier estimates of 10 years PFS with XPG rs2296147 CT/TT and CC genotypes in CRC patients. 
Table 3: Cox proportional hazards model analysis of associations between demographic and clinical data of patients and CRC prognosis

\begin{tabular}{|c|c|c|c|c|}
\hline \multirow[t]{2}{*}{ Variables } & \multirow[t]{2}{*}{$P$} & \multirow[t]{2}{*}{ HR } & \multicolumn{2}{|c|}{$95 \% \mathrm{CI}$} \\
\hline & & & Lower & Upper \\
\hline \multicolumn{5}{|l|}{10 years OS } \\
\hline BMI & 0.001 & 0.956 & 0.932 & 0.982 \\
\hline Therapeutic response & 0.000 & 2.835 & 2.509 & 3.203 \\
\hline Dukes stage & 0.000 & 3.613 & 3.226 & 4.046 \\
\hline Recurrence/Metastasis status & 0.000 & 4.710 & 3.993 & 5.556 \\
\hline \multicolumn{5}{|l|}{10 years PFS } \\
\hline Age & 0.002 & 0.990 & 0.984 & 0.996 \\
\hline Dukes stage & 0.000 & 2.016 & 1.817 & 2.238 \\
\hline
\end{tabular}

CRC, colorectal cancer; HR, hazard ratio; CI, confidence interval; OS, overall survival; BMI, body mass index; PFS, progression-free survival.

\section{SNP selected and genotyping}

Genomic DNA was obtained from the buffy coat fraction of each blood sample using a Qiagen Blood DNA Mini Kit (Qiagen Inc., Valencia, CA) according to the manufacturer's instructions. The candidate $X P G$ SNPs were selected as reported previously [40]. Finally, four SNPs (rs2296147, rs2094258, rs751402, rs873601) in the $X P G$ gene were chosen and included in the analysis. All these four selected SNPs were genotyped by using TaqMan realtime PCR as described previously [40]. For quality control, approximately $10 \%$ of the samples were randomly selected and repeatedly genotyped, and the results confirmed $100 \%$ concordance.

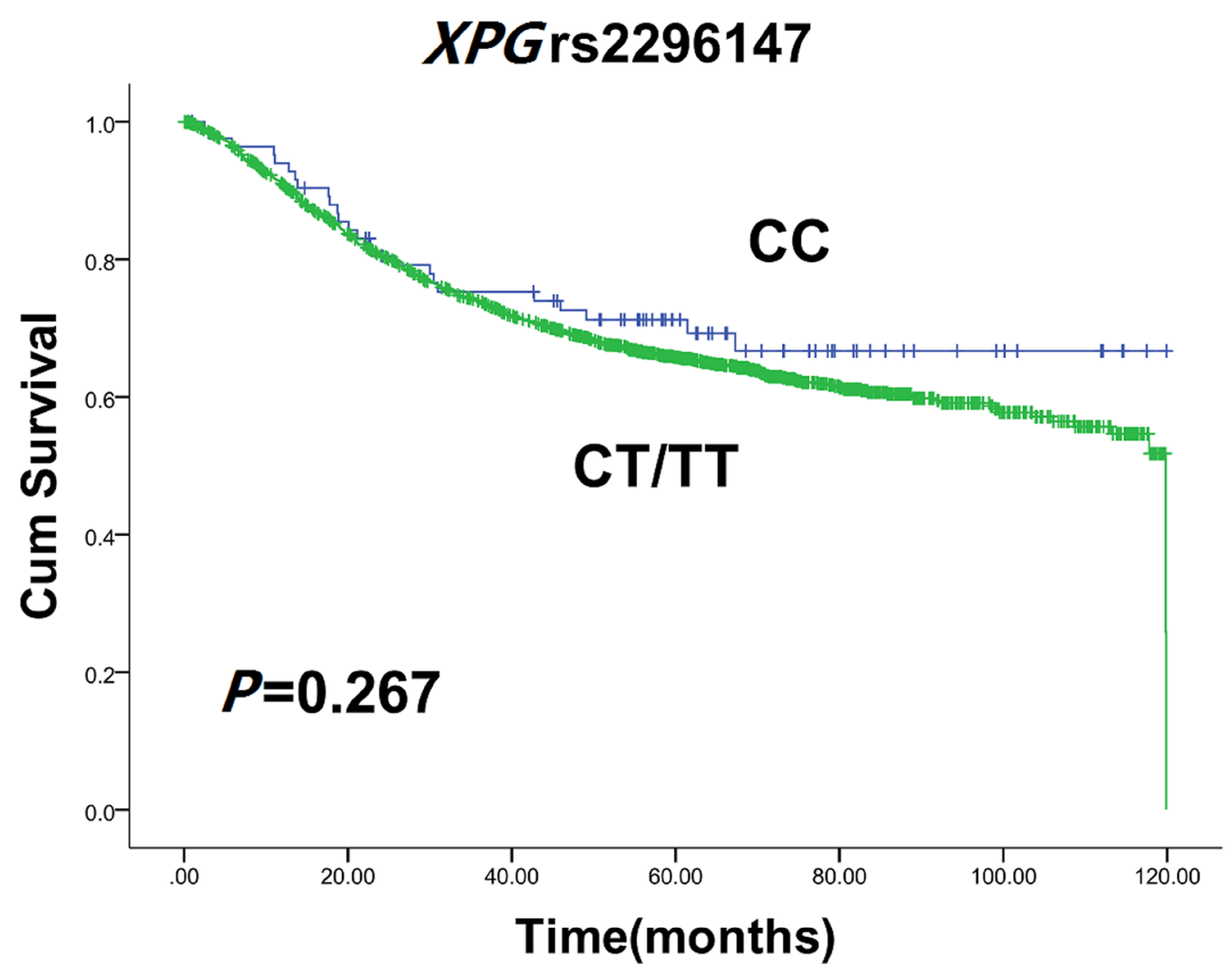

Figure 2: Kaplan-Meier estimates of 10 years OS with XPG rs2296147 CT/TT and CC genotypes in CRC patients. 
Table 4: Kruskal-Wallis analysis of associations between the demographic and clinical data of patients and genotypes of $X P G$

\begin{tabular}{|c|c|c|c|c|c|c|c|c|}
\hline \multirow[b]{2}{*}{ Variables } & \multicolumn{2}{|c|}{ rs2094258 } & \multicolumn{2}{|c|}{ rs2296147 } & \multicolumn{2}{|c|}{ rs751402 } & \multicolumn{2}{|c|}{ rs873601 } \\
\hline & $P^{a}$ & $P^{b}$ & $P^{a}$ & $P^{b}$ & $P^{1}$ & $P^{2}$ & $P^{1}$ & $P^{2}$ \\
\hline Sex & 0.693 & 0.399 & 0.721 & 0.231 & 0.799 & 0.313 & 0.172 & 0.122 \\
\hline Age & 0.107 & 0.026 & 0.666 & 0.544 & 0.121 & 0.054 & 0.063 & 0.106 \\
\hline Smoking status & 0.509 & 0.537 & 0.576 & 0.539 & 0.410 & 0.898 & 0.929 & 0.800 \\
\hline Drinking status & 0.299 & 0.510 & 0.170 & 0.271 & 0.282 & 0.713 & 0.671 & 0.789 \\
\hline BMI & 0.682 & 0.764 & 0.612 & 0.812 & 0.523 & 0.615 & 0.830 & 0.919 \\
\hline Therapeutic response & 0.538 & 0.865 & 0.230 & 0.181 & 0.232 & 0.550 & 0.824 & 0.963 \\
\hline Tumor site & 0.569 & 0.241 & 0.708 & 0.408 & 0.751 & 0.818 & 0.796 & 0.447 \\
\hline Dukes stage & 0.346 & 0.309 & 0.957 & 0.834 & 0.699 & 0.442 & 0.637 & 0.590 \\
\hline
\end{tabular}

BMI, body mass index.

a, $P$ values were calculated for 10 years OS.

b, $P$ values were calculated for 10 years PFS.

\section{Statistical methods}

OS was defined as the time from the date of pathologically confirmed to the date of death or last clinical follow-up. PFS was calculated from the date of the pathologically confirmed to the progression of the disease, death without progression, or last clinical follow-up. Numerical variable in this study were expressed as mean and percentage. Survival distributions were estimated by using the Kaplan-Meier method and difference in the survival was tested using the log-rank test. To estimate the association of the four XPG SNPs with PFS and OS in CRC, the HR and $95 \%$ CI were calculated by univariate Cox proportional hazards model. Multivariate Cox model were performed to compute adjusted HR and 95\% $\mathrm{CI}$, after adjusting for potential risk factors. Homozygous variant genotype severed as a reference group. All tests were two-sided and $P<0.05$ was considered to be significant. All statistics were conducted by SPSS 19.0 software.

\section{ACKNOWLEDGMENTS AND FUNDING}

This study was supported by grants from the National Natural Science Foundation of China (Grant No. 81502046), Special Financial Grant from the China Postdoctoral Science Foundation (Grant No. 2014T70836), the Natural Science Foundation of Guangdong Province (Grant No. 2015A030310324), and the National Science Fund for Distinguished Young Scholars (Grant No. 81325018).

\section{Authors' contributions}

All authors contributed significantly to this work. F.W., S.-D. Z., H.-M. X., X.-Z. L., W.-Q. X., and X.-Z. L. performed the research study and collected the data; F. W.,
R.-X. H. and T.-M. W. analyzed the data; J. H. and W.-H. J. designed the research study; F.W., J.-H. Z., J. H. and W.-H. J. wrote the paper, and F.W. and B.-H. X. prepared Figures 1 and Tables 1-3. All authors reviewed the manuscript. In addition, all authors approved the final draft.

\section{CONFLICTS OF INTEREST}

The authors declare no competing financial interests.

\section{REFERENCES}

1. Torre LA, Bray F, Siegel RL, Ferlay J, Lortet-Tieulent J \& Jemal A. Global cancer statistics, 2012. CA Cancer J Clin. 2015; 65:87-108.

2. Stintzing S. Management of colorectal cancer. F1000Prime Rep. 2014; 6:108.

3. Brenner H, Kloor M, Pox CP. Colorectal cancer. Lancet. 2014; 383:1490-1502.

4. Azeem S, Gillani SW, Siddiqui A, Jandrajupalli SB, Poh V, Syed Sulaiman SA. Diet and Colorectal Cancer Risk in Asia - a Systematic Review. Asian Pac J Cancer Prev. 2015; 16:5389-5396.

5. Hannan LM, Jacobs EJ, Thun MJ. The association between cigarette smoking and risk of colorectal cancer in a large prospective cohort from the United States. Cancer Epidemiol Biomarkers Prev. 2009; 18:3362-3367.

6. Cho S, Shin A, Park SK, Shin HR, Chang SH, Yoo KY. Alcohol Drinking, Cigarette Smoking and Risk of Colorectal Cancer in the Korean Multi-center Cancer Cohort. J Cancer Prev. 2015; 20:147-152.

7. Ma Y, Yang Y, Wang F, Zhang P, Shi C, Zou Y, Qin H. Obesity and risk of colorectal cancer: a systematic review of prospective studies. PLoS One. 2013; 8:e53916. 
8. Dong Y, Liu JW, Gao YJ, Zhou T, Chen YM. Relationship between DNA repair gene XPD751 single-nucleotide polymorphisms and prognosis of colorectal cancer. Genet Mol Res. 2015; 14:5390-5398.

9. Zhao Y, Deng X, Wang Z, Wang Q, Liu Y. Genetic polymorphisms of DNA repair genes XRCC1 and XRCC3 and risk of colorectal cancer in Chinese population. Asian Pac J Cancer Prev. 2012; 13:665-669.

10. Lindahl T, Wood RD. Quality control by DNA repair. Science. 1999; 286:1897-1905.

11. Bernstein C, Bernstein H, Payne CM, Garewal H. DNA repair/pro-apoptotic dual-role proteins in five major DNA repair pathways: fail-safe protection against carcinogenesis. Mutat Res. 2002; 511:145-178.

12. Marteijn JA, Lans H, Vermeulen W, Hoeijmakers JH. Understanding nucleotide excision repair and its roles in cancer and ageing. Nat Rev Mol Cell Biol. 2014; 15:465-481.

13. Scharer OD. XPG: its products and biological roles. Adv Exp Med Biol. 2008; 637:83-92.

14. Moreno V, Gemignani F, Landi S, Gioia-Patricola L, Chabrier A, Blanco I, Gonzalez S, Guino E, Capella G, Canzian F. Polymorphisms in genes of nucleotide and base excision repair: risk and prognosis of colorectal cancer. Clin Cancer Res. 2006; 12:2101-2108.

15. Monzo M, Moreno I, Navarro A, Ibeas R, Artells R, Gel B, Martinez F, Moreno J, Hernandez R, Navarro-Vigo M. Single nucleotide polymorphisms in nucleotide excision repair genes XPA, XPD, XPG and ERCC1 in advanced colorectal cancer patients treated with first-line oxaliplatin/ fluoropyrimidine. Oncology. 2007; 72:364-370.

16. Emmert S, Schneider TD, Khan SG, Kraemer KH. The human XPG gene: gene architecture, alternative splicing and single nucleotide polymorphisms. Nucleic Acids Res. 2001; 29:1443-1452.

17. Deng N, Liu JW, Sun LP, Xu Q, Duan ZP, Dong NN, Yuan Y. Expression of XPG protein in the development, progression and prognosis of gastric cancer. PloS one. 2014; 9:e108704.

18. Xue MH, Li GY, Wu XJ, Zhang CX, Zhang CF, Zhu KX. Genetic variability of genes in NER pathway influences the treatment outcome of gastric cancer. Int J Clin Exp Pathol. 2015; 8:5563-5569.

19. Zou HZ, Zhao YQ. XPG polymorphisms are associated with prognosis of advanced non-small cell lung cancer treated with platinum-based doublet chemotherapy. Genet Mol Res. 2015; 14:500-506.

20. Na N, Dun E, Ren L, Li G. Association between ERCC5 gene polymorphisms and breast cancer risk. Int J Clin Exp Pathol. 2015; 8:3192-3197.

21. Liang Y, Deng J, Xiong Y, Wang S, Xiong W. Genetic association between ERCC5 rs17655 polymorphism and lung cancer risk: evidence based on a meta-analysis. Tumour Biol. 2014; 35:5613-5618.

22. Yuli Y, Zhe S, Xia W, Siqing L, Zhenxuan W, Yu-Hua Z, Bing S, Jun-Wei C. XPG is a novel biomarker of clinical outcome in advanced non-small-cell lung cancer. Pak J Med Sci. 2013; 29:762-767.

23. Zhang T, Sun J, Lv M, Zhang L, Wang X, Ren JC, Wang B. XPG is predictive gene of clinical outcome in advanced non-small-cell lung cancer with platinum drug therapy. Asian Pac J Cancer Prev. 2013; 14:701-705.

24. Liu D, Wu HZ, Zhang YN, Kang H, Sun MJ, Wang EH, Yang XL, Lian MQ, Yu ZJ, Zhao L, Olopade OI, Wei MJ. DNA repair genes XPC, XPG polymorphisms: relation to the risk of colorectal carcinoma and therapeutic outcome with Oxaliplatin-based adjuvant chemotherapy. Mol Carcinog. 2012; 51 Suppl 1:E83-93.

25. Du H, Zhang X, Du M, Guo N, Chen Z, Shu Y, Zhang Z, Wang M, Zhu L. Association study between XPG Asp1104His polymorphism and colorectal cancer risk in a Chinese population. Sci Rep. 2014; 4:6700.

26. Sun K, Gong A, Liang P. Predictive impact of genetic polymorphisms in DNA repair genes on susceptibility and therapeutic outcomes to colorectal cancer patients. Tumour Biol. 2015; 36:1549-1559.

27. Negandhi AA, Hyde A, Dicks E, Pollett W, Younghusband BH, Parfrey P, Green RC, Savas S. MTHFR Glu429Ala and ERCC5 His46His polymorphisms are associated with prognosis in colorectal cancer patients: analysis of two independent cohorts from Newfoundland. PLoS One. 2013; 8:e61469.

28. Paszkowska-Szczur K, Scott RJ, Gorski B, Cybulski C, Kurzawski G, Dymerska D, Gupta S, van de Wetering T, Masojc B, Kashyap A, Gapska P, Gromowski T, Kladny J, et al. Polymorphisms in nucleotide excision repair genes and susceptibility to colorectal cancer in the Polish population. Mol Biol Rep. 2015; 42:755-764.

29. Mort R, Mo L, McEwan C, Melton DW. Lack of involvement of nucleotide excision repair gene polymorphisms in colorectal cancer. Br J Cancer. 2003; 89:333-337.

30. Zhu ML, Wang M, Cao ZG, He J, Shi TY, Xia KQ, Qiu LX, Wei QY. Association between the ERCC5 Asp1104His polymorphism and cancer risk: a meta-analysis. PLoS One. 2012; 7:e36293.

31. Mohrenweiser H. Survey of polymorphic sequence variation in the immediate $5^{\prime}$ region of human DNA repair genes. Mutat Res. 2007; 616:221-226.

32. Cartharius K, Frech K, Grote K, Klocke B, Haltmeier M, Klingenhoff A, Frisch M, Bayerlein M, Werner T. MatInspector and beyond: promoter analysis based on transcription factor binding sites. Bioinformatics. 2005; 21:2933-2942.

33. Blomquist TM, Crawford EL, Willey JC. Cis-acting genetic variation at an E2F1/YY1 response site and putative p53 site is associated with altered allele-specific expression of ERCC5 (XPG) transcript in normal human bronchial epithelium. Carcinogenesis. 2010; 31:1242-1250. 
34. He C, Duan Z, Li P, Xu Q, Yuan Y. Role of ERCC5 promoter polymorphisms in response to platinum-based chemotherapy in patients with advanced non-small-cell lung cancer. Anticancer Drugs. 2013; 24:300-305.

35. Hu W, Pan J, Zhao P, Yang G, Yang S. Genetic polymorphisms in XPG could predict clinical outcome of platinum-based chemotherapy for advanced non-small cell lung cancer. Tumour Biol. 2014; 35:5561-5567.

36. Yang B, Chen WH, Wen XF, Liu H, Liu F. Role of DNA repair-related gene polymorphisms in susceptibility to risk of prostate cancer. Asian Pac J Cancer Prev. 2013; 14:5839-5842.

37. Zhang XJ, Liu P, Zhu F. Polymorphisms of DNA repairrelated genes with susceptibility and prognosis of prostate cancer. Genet Mol Res. 2014; 13:4419-4424.
38. Duan Z, He C, Gong Y, Li P, Xu Q, Sun LP, Wang Z, Xing C, Yuan Y. Promoter polymorphisms in DNA repair gene ERCC5 and susceptibility to gastric cancer in Chinese. Gene. 2012; 511:274-279.

39. Yang WG, Zhang SF, Chen JW, Li L, Wang WP, Zhang XF. SNPs of excision repair cross complementing group 5 and gastric cancer risk in Chinese populations. Asian Pac J Cancer Prev. 2012; 13:6269-6272.

40. He J, Qiu LX, Wang MY, Hua RX, Zhang RX, Yu HP, Wang YN, Sun MH, Zhou XY, Yang YJ, Wang JC, Jin L, Wei QY, et al. Polymorphisms in the XPG gene and risk of gastric cancer in Chinese populations. Hum Genet. 2012; 131:1235-1244. 